\title{
UNA ACCIÓN POLÍTICA REALISTA Y SENSATA HACIA ESPAÑA: FRANCO, EL RÉGIMEN Y LA OPOSICIÓN EN LA CORRESPONDENCIA DIPLOMÁTICA NORTEAMERICANA, 1944-1947
}

A realistic and cautious course of action towards Spain: Franco, the regime and the opposition in the American diplomatic correspondence, 1944-1947

\author{
ÁLVARO FERRARY \\ Universidad de Navarra \\ aferrary@unav.es \\ Cómo citar/Citation \\ Ferrary, Á. (2021) \\ Una acción política realista y sensata hacia España: Franco, el régimen y \\ la oposición en la correspondencia diplomática norteamericana, 1944-1947. \\ Historia y Política, 46, 293-320 \\ doi: https://doi.org/10.18042/hp.46.11
}

(Recepción: 06/03/2020; evaluación: 05/06/2020; aceptación: 17/07/2020; publicación: 30/11/2021)

\section{Resumen}

Este texto se articula en torno a la correspondencia oficial mantenida entre el Departamento de Estado y la embajada de los EE. UU. en Madrid durante la segunda mitad de los ańos cuarenta preservada en los National Archives Records Administration (NARA). Hemos centrado nuestra atención en este rico y abundante material con el propósito de poner de relieve la extraordinaria insistencia con que en dichos informes se reiteraba la idea de que la mejor fórmula, si acaso no la única, de generar condiciones favorables al desarrollo de una apertura política en España con la que procurar un tránsito de la dictadura a la democracia consistía en abstenerse de promover iniciativas amenazantes y punitivas contra el orden vigente en el país. Con diverso énfasis, y por encima de sus respectivas diferencias de carácter (eventualmente 
también de trayectoria), tanto Cartlon J. H. Hayes como Norman Armour, o bien William W. Butterworth, Philip W. Bonsal y Paul T. Culbertson se apoyaron en esos argumentos para manifestarse partidarios de aplicar a España una política flexible, realista y prudente. La única capaz — pensaban_ de generar las condiciones que el país requería para ir dejando atrás sus muchas contradicciones actuales e históricas, y para emprender un tránsito hacia fórmulas de convivencia democrática.

\title{
Palabras clave
}

Estados Unidos; España; democracia; dictadura; oposición.

\begin{abstract}
This text is fundamentally built upon the diplomatic correspondence held between the State Department and the US Embassy in Madrid during the second half of the 40s (preserved at the National Archives Records Administration (NARA). Our attention has been focused on this rich and abundant material with the aim of highlighting how emphatically was reiterated the proposition in American political channels that refraining from carrying out threatening (let alone punitive) actions against Francoist Spain was the best formula, if not the only one, to produce favourable conditions for a transition from Dictatorship to Democracy in the country. Even though each one through their own lenses and personal outlook, both Carlton J.H. Hayes and Norman Armour, as well as William W. Butterworth, Philip W. Bonsal and Paul T. Culbertson (successively heading the American Mission at the time) reached the conclusion that good doses of pragmatism, flexibility and perseverance were required to successfully face the Spanish question. Only by doing this, they thought, the conditions the country needed to overcome its deep-rooted social and historical contradictions and shortcomings might be met.
\end{abstract}

\section{Keywords}

United States; Spain; democracy; dictatorship; opposition. 


\section{SUMARIO}

I. INTRODUCCIÓN. II. EL INFORME DE SEPTIEMBRE DE 1944. III. UN NUEVO RESPONSABLE AL FRENTE DE LA EMBAJADA EN MADRID: 1. El informe de octubre de 1945. 2. Los moderados del Régimen. IV. UNOS MESES CRUCIALES: 1. El momento de pisar el acelerador. 2. Un último esfuerzo antes del giro. V. CONCLUSIÓN. BIBLIOGRAFía.

\section{INTRODUCCIÓN}

Como desde hace unos cuarenta años ha ido quedando ampliamente acreditado en la historiografía ${ }^{1}$, de todas las instancias implicadas en la ejecución de la acción exterior norteamericana (el Departamento de Estado, el Departamento de Defensa o Pentágono, los órganos asesores e incluso la misma Presidencia) fue la primera citada la que durante el período 1944-1947 llevó el peso de la presión política contra Franco ${ }^{2}$. Ahora bien, que la animadversión hacia la figura de Franco y hacia todo lo que éste representaba se convirtiera en un sentimiento claramente predominante en el Departamento de Estado ${ }^{3}$, no fue suficiente para resguardar a la política de los EE. UU. hacia España de ciertos rumbos erráticos o para prevenirla de continuos bandazos, por lo menos hasta finales de $1947^{4}$. Varios factores han sido destacados como los causantes de esa situación. Según Edwards, parte de dichas inconsistencias se debieron a los deseos de Washington de contentar a la vez a dos actores tan opuestos entre sí ante la cuestión española como Francia y Gran Bretaña Incidiendo en ese mismo punto, Hualde se ha referido por su parte a la «inestable» política del Departamento de Estado, «producida por los juegos malabares que debía hacer para contentar a todos los actores implicados: desde París y Londres [...] hasta el estamento militar, pasando por las posiciones más intermedias» ${ }^{6}$. Asimismo, siguiendo una línea argumental ya iniciada por

Cortada (1980); Viñas (1981); Brundu Olla (1985), y Portero (1989).

Jarque Iñíguez (1998) y Thomàs (2011).

3 Bowen (2016 y 2017) y Dunham (1996): 31. Entre 1945-1955, William B. Dunham trabajó en la Division of West European Affairs del Departamento de Estado como Desk Officer para Portugal y Assistant Desk Officer para España.

4 Liedtke (1998) y Hualde Amunarriz (2016).

5 Edwards (1999): 63-64.

6 Hualde Amunarriz (2016): 263. 
el mencionado Edwards a partir de fuentes diplomáticas británicas, el investigador vasco ha aludido también a la división existente en el seno del Departamento de Estado entre los funcionarios más transigentes con Franco y con España y los más tozudamente antifranquistas, partidarios de llegar al límite de lo posible para forzar la caída del dictador español ${ }^{7}$. Aparte de lo dicho, otros tres factores han sido también habitualmente señalados en la historiografía en relación con las ya referidas inconsistencias americanas a la hora de encarar el asunto español. En primer lugar, la baja moral, la inefectividad ${ }^{8}$, así como la notable desorganización y anarquía interna reinante en el Departamento, al menos hasta la llegada de George Marshall a su dirección? . Segundo, la continua (y desconcertante) sucesión de avances y de retrocesos aparentemente cosechados por los grupos de la oposición en su afán por presentarse como alternativa sólida y creíble a Franco ${ }^{10}$. En tercer lugar, el muy discreto nivel de importancia reservado a la cuestión española en la agenda política y diplomática de los Estados Unidos, lo que en contraste con otros asuntos más acuciantes al parecer favoreció una aproximación al tema español con mayores discontinuidades e inconsecuencias de las debidas ${ }^{11}$.

Sin embargo, a quienes por obvias consideraciones profesionales el tema espańol no se les presentó como un asunto menor o secundario fue a los representantes diplomáticos norteamericanos en España. En particular a quienes durante el decisivo período 1944-1947 se situaron al frente de la embajada de los Estados Unidos de América en Madrid. En ellos, a través de algunos de sus informes y despachos, vamos a centrar nuestra atención. Nuestro propósito es poner de relieve un factor que creemos no se ha resaltado lo suficientemente en la historiografía: la machacona insistencia con que en dichos informes se reiteraba la idea de que la mejor fórmula, si acaso no la única, de generar condiciones favorables al desarrollo de una apertura política en España - con la que promover un tránsito de la dictadura a la democracia- exigía limitar al máximo las iniciativas hostiles o punitivas contra el orden vigente en el país. Pues, al margen de lo muy precario e insatisfactorio que les pareciera dicho orden, la fractura social provocada por la guerra civil y por la represión había sido de tal calibre, y continuaba estando tan a flor de piel, que se temían que una presión excesiva desde el exterior contra el régimen solo sirviera para que se reactivasen las posiciones más

\section{Ibid.: 136-137.}

8 Miscamble (1992).

$9 \quad$ Hualde Amunarriz (2016): 73.

10 Alonso García (2004) y Yuste de Paz (2005).

11 Termis Soto (2005) y Bowen (2017). 
maximalistas en ambos bandos, y España volviera a precipitarse por el abismo de un nuevo enfrentamiento fratricida.

De hecho, en los informes enviados desde Madrid a la Secretaría y al Departamento de Estado desde el mes de septiembre de 1944 hasta diciembre de 1947 — esto es, durante todo el período de mayor hostilidad y dureza norteamericana frente a Franco y el franquismo ${ }^{12}$ - fue un lugar común (aun con diversos matices) la afirmación de la premisa de que la única opción viable y realista de promover en España un régimen de representación y de libertades ineluctablemente había de consistir en partir de la legalidad impuesta por los vencedores en la guerra civil en 1939, no en una restauración más o menos inmediata o más o menos integral de la legalidad conculcada de manera violenta por estos en 1936. Habría además que añadir que en lo sustancial dicha posición quedó prefigurada muy pronto, meses antes incluso de que concluyera la Segunda Guerra Mundial, y que — lejos de verse alterada — esta no hizo sino reforzarse con el paso del tiempo.

\section{EL INFORME DE SEPTIEMBRE DE 1944}

Precedido de otros muchos análisis, al largo informe enviado por Carlton Hayes a la Secretaría de Estado en septiembre de 1944 se le atribuyó una especial relevancia, tanto por la gran cantidad de datos e informaciones de muy variada procedencia sobre los que se sustentaba como por la importancia de la cuestión abordada: cómo promover una política realista hacia España en las circunstancias vigentes ${ }^{13}$. Para ello, un primer factor que había de tenerse en cuenta — se destacaba — era que «[el país] en su conjunto se halla en un estado

12 Carlton J. H. Hayes había accedido al cargo de embajador en España en mayo de 1942. En enero de 1945 sería sustituido por Norman Armour, quien finalizaría su misión en diciembre de 1945. En su lugar fueron sucesivamente tres encargados de Negocios quienes se situaron al frente de la embajada en Madrid: los citados Butterworth (de diciembre de 1945 a marzo de 1946), Bonsal (de marzo de ese ańo a junio de 1947) y Culbertson (de junio de 1947 a diciembre de 1950). Concretamente, sobre el papel que desempeñó Hayes durante su estancia en España y sobre su posterior actividad pro-Franco una vez vuelto a su país, ver Thomàs (2016).

13 NARA, RG59/52/1944-1949/Decimal Files/BOX5233 (852.00/9-2644) De: Carlton J. H. Hayes A: Secretario de Estado. Septiembre 26, 1944. Aunque Hayes ha sido presentado en ocasiones como una figura demasiado indulgente con la persona de Franco, hay que señalar que en el informe de septiembre no se alejaba en sus aspectos más esenciales de los que elaborarían sus sucesores a partir de enero de 1945. 
de insatisfacción con el Gobierno actual y en espera de un cambio». Insistía Hayes en que en ese diagnóstico habían coincidido todos los despachos consulares utilizados para la elaboración del informe, además de confirmarse también en las fuentes de información de la embajada. Según todo aquel caudal de información, solo cabía concluir que «sin ninguna duda en su gran mayoría la opinión española, quizás tanto como un ochenta y cinco o un noventa por ciento, es hostil a la Falange y espera que el general Franco, por propia iniciativa u obligado a ello, al final acabe siendo desbancado por algún otro régimen $»^{14}$. La impresión de que el régimen, tal y como existía, no podría aguantar el tirón de la ya dada por segura derrota militar del Eje era, a juicio de Hayes, tan fuerte, y se encontraba tan generalizada, que «existe la [asimismo] extendida creencia de que la presente configuración política en España es temporal y transitoria y que inevitablemente esta debe y se verá modificada ${ }^{15}$. Pero, ¿cómo y en qué condiciones había de emprenderse dicho cambio? Era en relación con este punto en donde residía la tesis central del informe de septiembre. Se postulaba con gran claridad la idea de que la vía más sensata para promover un cambio consistía en partir de la legalidad existente, no en quebrantarla. Las razones que se esgrimían para sostener dicha posición eran de naturaleza mental y psicológica, política e histórica. Las tres, aunque no siempre con idéntico grado de énfasis, se reiterarían en informes, análisis y comunicaciones ulteriores durante todo este período.

Las razones mentales o psicológicas aducidas apuntaban a «la memoria vívida [...] de los excesos, de los trastornos y de las luchas partisanas que marcaron los años finales de la República, y especialmente de las matanzas y destrucción que se produjeron durante tres años de terrible guerra civil». La consecuencia de ello era — se decía - la generalización en todos los niveles de la sociedad española de unas actitudes resueltas a evitar a toda costa vacíos de poder y de rechazo de eventuales quiebras de la legalidad ${ }^{16}$. Lo más llamativo, se seguía afirmando, era que esas posiciones no eran solo privativas de la Falange. Tampoco se extendían únicamente a los monárquicos, a los conservadores, a las grandes fortunas, a los hombres de negocios o a los dirigentes eclesiásticos, sino que eran asimismo palpables en «muchos izquierdistas —republicanos, socialistas, obreros manuales y campesinos—». Concluía Hayes que el terror que suscitaba la posibilidad de un regreso al período anterior a 1939 era de tal magnitud que una gran mayoría de españoles no dudaban

\footnotetext{
Ibid.: 1-2. Las cursivas son nuestras.

Íd.

Ibid.: 2.

17 Íd.
} 
en anteponer «el orden de hoy — por muy precario y gravoso que fuera— a la libertad de mañana». Ante esa situación, seguía diciendo que «únicamente en el caso de que se lograra impulsar una transición hacia un Gobierno constitucional pacífica y en orden cabía esperar que la gran mayoría de los españoles prestara su apoyo [a dicho proceso] $\aleph^{18}$.

En el capítulo de razones políticas se realzaban dos factores: la situación de la oposición política y la amenaza revolucionaria que se atribuía a los comunistas. En relación con lo primero, el panorama que se describía difícilmente podía resultar más desolador. De las fuerzas de la oposición se destacaba la desconcertante amplitud de sus posicionamientos políticos, la constante tendencia de sus grupos al enfrentamiento interno, así como "la inexistencia de un acuerdo u organización operativa entre ellos ${ }^{\prime 1}$. A lo anterior se sumaba que, con «la posible excepción de los comunistas y de los nacionalistas vascos», los grupos de la oposición se hallaban internamente fragmentados en un conjunto de tendencias muy variadas, contradictorias y mal avenidas entre sí. De modo que, se concluía, «existen varios grupos diferentes de socialistas, de republicanos, de monárquico, [muy] celosos cada uno de los otros y [aparecen] movidos por ese individualismo que es el rasgo más sobresaliente de los espańoles $[\ldots] \aleph^{20}$. El cual asimismo se revelaba, según se indicaba, en la falta entre los líderes de la oposición a Franco de «una personalidad fuerte y respetada capaz de tender puentes, de atraerse el entusiasmo de las masas y de inspirar concienciación y unidad de propósito $»^{21}$. Si la situación descrita ya era de por sí sumamente desalentadora, en nada contribuía a mejorarla esa suerte de fatalismo paralizante en el que, según Hayes, se hallaba sumida la oposición debido a «la idea tan extendida [entre sus representantes] [...] de que no tienen que actuar por sí mismos [,] sino que sus objetivos respectivos pueden y serán conseguidos gracias a la ayuda exterior ${ }^{22}$. Sin embargo, de esa situación de parálisis al menos un grupo sí que parecía haber sabido zafarse: el de los comunistas espańoles. Estos, se leía en el informe, pese a ser una pequeña minoría (si bien «una minoría en expansión»), «son los más fanáticos y los mejor organizados»; además de distinguirse por sus notables habilidades de infiltración en muy distintos y variados ámbitos, gracias a una hábil puesta en práctica de la «técnica del caballo de Troya ${ }^{23}$. Aunque en lo que verdaderamente se
Ibid.: 3 .
Íd.
Íd.
Ibid.: 4.
Ibid.: 5 .
Ibid.: 3 . 
distinguían los comunistas del resto — se seguía diciendo- era en que contaban con una dirección férrea (la proporcionada por Moscú) y con la ayuda «moral, financiera, y quizás también militar, procedente de la todopoderosa Rusia». De ahí, en suma, que «se tenga el temor de que [los comunistas] sean quienes se hagan con el control dictatorial de todo régimen liberal que llegue a suplantar al régimen de Franco ${ }^{24}$. En cuanto a las razones históricas esgrimidas en contra de la idea de una eventual quiebra de la legalidad vigente, cabría mencionar sobre todo el papel histórico que se atribuía al Ejército en el funcionamiento del orden político español. La posición que se adoptaba ante esta cuestión era rotunda: el Ejército, se leía en la página 5, representa «una posición clave». De ello se señalaba que daba cumplida fe que «desde hace más de un siglo ningún Gobierno se ha mantenido en España sin el apoyo militar [...] y hay pocas dudas de que su papel no continuará siendo decisivo en el futuro» ${ }^{25}$. Para Hayes, el Ejército era «la única organización en Espańa capaz de efectuar por vías relativamente ordenadas una transición hacia una forma representativa y constitucional del Gobierno $»^{26}$. El problema consistía en que, hasta la fecha, ni entre las filas de la oficialidad ni entre los componentes del Estado Mayor había indicio alguno de disidencia interna. Sin embargo, sí cabía señalarse — se puntualizaba en las consideraciones finales - que «el Gobierno de Franco y sus apoyos, incluida la Falange y el Ejército, comienzan a ser plenamente conscientes de las implicaciones de la finalización de la guerra con una victoria de los Aliados». Incurriendo en un evidente wishful thinking pensaba Hayes que aquella circunstancia no resultaba en nada baladí, puesto que — argumentaba el embajador - en un mundo de postguerra cada vez "más y más inclinado hacia la izquierda», y en el que ya no cabía pensar por más tiempo en que solo bastaba con incrementar las medidas represivas contra los críticos para perpetuarse en el poder, «quizás Franco o el Ejército aún actuarán a tiempo para efectuar una evolución desde la Falange a un Gobierno constitucional ${ }^{27}$.

\section{UN NUEVO RESPONSABLE AL FRENTE DE LA EMBAJADA EN MADRID}

Como ya se ha señalado, estas evaluaciones sobre las condiciones políticas imperantes en España y sobre sus posibilidades de evolución, se iban a

$\begin{array}{ll}24 & \text { Íd. } \\ 25 & \text { Ibid.: } 5 . \\ 26 & \text { Íd } \\ 27 & \text { Ibid.: } 7 .\end{array}$


mantener sin alteraciones notables tras la marcha de Hayes, aunque con una salvedad no poco importante: si éste en ocasiones parecía haberse conducido con alguna ambigüedad (o clara indulgencia, según muchos de sus críticos en la izquierda liberal norteamericana) en relación a la figura de Franco - o acerca de si el dictador espańol debía o no a corto plazo apartarse del poder-, la posición que en estas dos cuestiones se iba a adoptar tras la llegada de Norman Armour a Madrid resultó mucho más tajante; en línea con el militante antifranquismo que se respiraba en el entorno del presidente y del Departamento de Estado ${ }^{28}$. Todo lo cual, sin embargo, tal vez no sea suficiente para atribuir a la sustitución de Hayes por Armour una clara solución de continuidad. Una prueba de ello pareció representarlo el informe que el nuevo embajador firmaba y hacía llegar a Washington en octubre de $1945^{29}$.

\section{EL INFORME DE OCTUBRE DE 1945}

En efecto, en términos muy semejantes a los empleados por Hayes, Armour se refería al poderoso hastío de guerra (war-weariness) de la inmensa mayoría de los españoles. Hasta el punto, precisaba el embajador, que «todo grupo o facción dentro de España —o toda potencia extranjera, por muy altruistas que sean sus intenciones- que subestime esta neurosis nacional hoy tan presente y abra las compuertas de otra guerra civil, lo pagará caro en la estima del pueblo español ${ }^{30}$. En cuanto al estado de la oposición política, los aspectos que se enfatizaban en el informe básicamente eran los mismos que los destacados por Hayes meses atrás. Se aludía a la inexistencia de acuerdos o propósitos comunes entre los grupos de la derecha y de la izquierda. Se hablaba de la falta de una organización con capacidad para hacer caer al

28 Bowen (2017): 57 y ss.

29 En un despacho anterior el representante norteamericano había lanzado la advertencia de que «en una grave responsabilidad incurriría todo individuo o toda nación que consciente o inconscientemente [con su acción] contribuyera a hacerla [una nueva guerra civil] estallar». Según Armour, para propiciar esa «evolución pacífica desde dentro que deseamos» era imprescindible tener en cuenta que "[aunque] en la superficie la situación en apariencias es de calma [...] bajo la superficie el odio está a flor de piel; la discordia tanto personal como política es enconada y abundante; y otra guerra civil en España sería de nuevo trágicamente cruel e inútil». NARA RG59/52/19441949/Decimal Files/BOX6334 (852.00/5-1945): «The Current Spanish Political Scene», May 19, 1945, p. 3.

30 NARA RG59/52/1944-1949/Decimal Files/BOX6335 (852.00/10-845): An Appreciation of the Spanish Political Situation, October 8, 1945, p. 2. 
régimen vigente o, lo que aún era peor, para asumir la responsabilidad de gobierno en caso de que la oposición se encontrara repentinamente ante esa tesitura. Se hacía mención a la flagrante carencia de líderes capaces de atraer a la gente, de fijar un programa de acción conjunto o de formar un Gobierno. De la oposición en el exilio se destacaba su propensión al faccionalismo y su falta de contacto con la realidad. También se insistía en que toda la oposición en su conjunto se encontraba intoxicada por «el virus de la creencia de que la intervención extranjera "salvará los muebles"[;] de que Gran Bretaña o los Estados Unidos "darán el paso adelante" para lograr que se venga abajo ese régimen de Franco que ellos mismos son incapaces de derrocar» ${ }^{31}$. La necesidad imperiosa de no hacer nada que cuestionara la posición de centralidad que ocupaba el Ejército era asimismo objeto de gran atención. En efecto, echando mano casi de las mismas palabras empleadas por Hayes once meses antes, Armour se refería a cómo

durante más de un siglo ningún Gobierno español ha llegado al poder o ha sido capaz de sobrevivir mucho tiempo sin el apoyo del Ejército español [...]. Debe recalcarse que la decisiva importancia de la actitud del Ejército es ampliamente reconocida por los líderes de la oposición tanto monárquica como republicana [...] [quienes] admiten a las claras que su propio éxito depende en gran medida de conseguir el divorcio de elementos importantes del Ejército de su lealtad a Franco. Cosa que hasta la fecha no se ha conseguido ${ }^{32}$.

Tampoco se olvidaba Norman Armour de abordar otro de los temas centrales del informe de septiembre de 1944. Esto era, el del numéricamente muy limitado entusiasmo que Franco despertaba entre los españoles, si bien se volvía a reiterar que una mayoría de españoles anteponían la seguridad y el orden a cualquier otra consideración política ${ }^{33}$.

\section{LOS MODERADOS DEL RÉGIMEN}

Al margen de los muchos puntos en común entre los dos informes, un tema sobresalía con renovado énfasis en el de octubre de 1945. Este iba a ser a partir de entonces objeto de una atención creciente, como demuestran otros despachos posteriores del mismo Armour, así como no pocos de los debidos a

\footnotetext{
31 Ibid.: 4-5.

32 Ibid.: 2.

33 An Appreciation of the Spanish Political Situation..., p. 10.
} 
los tres encargados de Negocios que le iban a suceder al frente de la embajada en Madrid. La razón de ello hay que encontrarla en las manifestaciones de condena del régimen español que siguieron a la resolución de San Francisco y a la declaración de Potsdam. O más concretamente, en la honda preocupación que causó en la embajada las reacciones defensivas que dichos actos de condena estaban provocando entre importantes sectores moderados del régimen, los cuales - se precisaba-, dada la situación de división e impotencia en la que se hallaba la oposición, «son los únicos patrocinadores posibles de una evolución politica pacifica ${ }^{34}$. Entre los componentes de esos sectores incluía Armour a los militares, a miembros del clero y de Acción Católica, a los hombres de negocios y a las grandes fortunas. De todos ellos se decía que «están ansiosos por que se eliminen lo antes posible los rasgos totalitarios del régimen"; que «celebran cualquier medida procedente de casi donde sea que se dirija en contra de la Falange y de sus proyectos», y que fundan sus deseos de cambio «en el poder para hacerlo efectivo» ${ }^{35}$. El problema, señalaba el representante estadounidense, residía en que "las declaraciones [de condena internacional] han parecido desafiar, no a la dictadura actual, sino a la victoria nacionalista en la Guerra Civil [,] asi como a todas fuerzas que participaron en ellaw ${ }^{36}$. De modo que, al no haberse sabido establecer estas imprescindibles distinciones, la inmediata consecuencia de esa campaña internacional — apuntaba el embajador- había consistido en reforzar a los que se oponen al cambio (esto era, a los radicales de Falange) a costa de los partidarios del mismo, quienes se habrían visto debilitados al verse obligados «a hacer piña con aquellas mismas fuerzas que [ellos] están intentando sacar del poder» para hacer frente conjuntamente a la situación exterior ${ }^{37}$. Para Armour, en consecuencia, era preciso calibrar mejor las acciones que se emprendieran contra Espańa y esforzarse

Ibid.: 9. Las cursivas son nuestras.

35 Íd

36 Íd. Es muy significativo que las ocho líneas del párrafo de donde proceden las palabras reproducidas en el texto se resaltaran en el documento original con tres rayas paralelas trazadas en lápiz rojo. La conjetura de que el autor de esas líneas fuera el propio destinatario oficial del despacho - esto es, el secretario de Estado, James $\mathrm{F}$ Byrnes- es más que plausible. Las cursivas en el texto son nuestras.

37 Ibid.: 9. Cuatro meses antes, Armour había recomendado que las posiciones antiFranco y anti-Falange, «que constituye la base de la política del Departamento [de Estado] hacia España», se concentren sobre todo «en atacar a la fascista Falange» y que, «al menos de momento [...] [se eviten] ataques frontales personalmente contra Franco", al objeto de no generar alarmas entre los representantes del Ejército y de la Iglesia o entre una abrumadora mayoría de españoles moderados que se oponían «al papel desempeñado por la Falange y a sus arbitrarios métodos policiales». NARA 
por evitar que se convirtieran en un revulsivo a favor del Gobierno dictatorial de Franco. De lo contrario, advertía el Embajador, se vería seriamente comprometida «la política que el presidente Roosevelt me encomendó en su carta [de marzo de 1945]», consistente en «socavar el carácter totalitario del régimen español actual» y propiciar «el arranque de un cambio pacífico en España». Circunstancia — añadía - que solo se logrará mediante «la presión que se ejerza sobre Franco por parte de sus principales aliados [,] entre los cuales el Ejército español y la Iglesia son los más importantes» ${ }^{38}$.

Dejándose llevar por un optimismo apenas menos ingenuo que el de su predecesor en el cargo, Armour parecía sentirse seguro de que la sola contemplación de las sombrías perspectivas políticas y económicas que aguardaban a España a causa de su creciente marginación internacional iba a ser suficiente para que, a no tardar mucho, esos sectores moderados emprendieran una labor de presión contra Franco y contra la Falange. La cual, en un corto plazo, habría de producir la salida de Franco del poder, la eliminación del partido y, de manera concatenada, el arranque de un proceso lento, suave y progresivo de cambio hacia un nuevo marco de libertades democráticas.

\section{UNOS MESES CRUCIALES}

No menos ingenuos que Norman Armour se iban a mostrar quienes, a partir de diciembre de 1945, ocuparían la dirección de la misión diplomática de los Estados Unidos de América en Madrid. El primero cronológicamente en hacerlo fue el diplomático de carrera William Walton Butterworth. Tras haber pasado por la embajada norteamericana en Londres, en julio de 1942 se había incorporado simultáneamente a la legación en Lisboa y a la embajada en Madrid como primer secretario. Inicialmente, se encargó de temas económicos relacionados con el esfuerzo de guerra norteamericano — más concretamente del importante tema del wolframio-. En marzo de 1944 fue nombrado consejero de la embajada en sustitución de Willard L. Beaulac, el más estrecho colaborador de Hayes, que había sido nombrado embajador en Paraguay. Continuaría ejerciendo el cargo de consejero durante el mandato de Armour, convirtiéndose en encargado de Negocios ad interim a raíz de su marcha - lo que en la ausencia de un nuevo embajador al frente en la práctica equivalía a asumir las tareas de dirección-.

\footnotetext{
RG59/52/1944-1949/Decimal Files/BOX6334 (852.00/5-1945): «The Current Spanish Political Scene», May 19, 1945, pp. 3-4.

Ibid.: 11.
} 
Cesó en el cargo en marzo de 1946, al ser nombrado counselor en la misión de los EE. UU. en Nanking ${ }^{39}$.

Aunque Butterworth permaneció como encargado de Negocios apenas cuatro meses, contaba con el importante bagaje de sus más de cuatro años de intenso trabajo en España, circunstancia que le había permitido adquirir un grado notable de conocimiento tanto de las interioridades del régimen como de la atmósfera general del país. La posición que adoptó desde sus primeros despachos fue muy continuista con la de Armour ${ }^{40}$. En particular en relación con la preocupación, ya manifestada por su predecesor, por no crispar con gestos y acciones de hostilidad internacional a esos mismos sectores moderados señalados en el informe de octubre de 1945 como «los únicos patrocinadores posibles de una evolución política pacífica». Veinticinco años más tarde, con gran viveza expresiva, recalcaría Butterworth que las prisas y un exceso de presuntuosidad (a lo había que había que sumar - añadía - una comprensión no siempre suficiente de las complejidades españolas ${ }^{41}$ era lo que había llevado a los Estados Unidos a acompasar su política hacia España a unas formas y actuaciones inconvenientes que causaban un gran perjuicio a sus propios intereses y objetivos. El problema era, recordaba Butterworth, que

39 La carrera posterior de Butterworth sería muy dilatada y exitosa. Sobre su figura ver McKinzie y Wilson (1971).

40 Dicha continuidad quedaba patente, por ejemplo, en el telegrama de 8 de enero de 1946, en el que incidía en la idea de que el escaso entusiasmo que concitaba Franco no era sinónimo de oposición efectiva a su figura. De lo que concluía que la única posibilidad real de hacer caer a Franco dependía de un Ejército sobre el que este ejercía un control férreo (NARA RG59/52/1944-1949/Decimal Files/BOX6336, 852.00/1-846. De: Amembassy, Madrid A: Secretary of State, January 8, 1946, pp. 5-6). Asimismo, en febrero de 1946 el encargado de Negocios recordaba que las muestras de condena internacional contra Franco «han tenido el efecto de movilizar a favor del régimen a importantes elementos que, si bien [son] esencialmente contrarios al Gobierno de Franco, [entienden que] esas condenas se han diseñado no sólo para derrocar a Franco, sino también para anular la victoria de los nacionales y hacer regresar al poder a aquellos que habían perdido la guerra» (NARA RG59/52/19441949/Decimal Files/BOX6337, 852.00/2-1546. De: Amembassy A: Secretaría de Estado, febrero 15, 1946, p. 16).

41 Ya en su informe de octubre de 1945, Armour había insistido en que «los problemas españoles no podían ser definidos mediante axiomas, ni mediante epigramas ni silogismos [...] [pues] un espíritu autóctono tan individualista [como el del espańol] $-\mathrm{y}$ la consiguiente convicción de que a cada idea política le corresponde contar con un partido político — no hace sino señalar el principio de [todos] los problemas» [An Appreciation of the Spanish Political Situation..., p. 10]. 
«nos habíamos creído que solo teníamos que mover una mano para que Franco se retirara de escena». Pero lo que ocurrió, seguía diciendo, fue exactamente lo contrario: «Cuanto más intentábamos amenazar a Franco mayor cohesión provocábamos entre los componentes del muy heterogéneo grupo que le apoyaba ${ }^{42}$. Para el exencargado de Negocios los males provenían de que aquella política no era solo «el reflejo de una ilusión que giraba sin parar alrededor de Washington", sino que también era un reflejo «de uno de nuestros primeros delirios de grandeza, de un subidón de calentura a la cabeza que nos llevó a pensar que podíamos actuar como el gran lobo malo, y que podíamos soplar y soplar hasta hacer volar cualquier cabaña» ${ }^{43}$. Como ya se ha señalado, en el mes de marzo de 1946 Butterworth era repentinamente reclamado para integrarse en la misión de los Estados Unidos en China. Su puesto sería de inmediato ocupado por Philip W. Bonsal, recientemente integrado en el staff de la embajada en Madrid como primer secretario. La labor de Bonsal iba a coincidir con el período más delicado para la supervivencia de la dictadura española de toda la postguerra, como de hecho atestiguan la declaración sobre España de la Asamblea General de la ONU y el cierre de la frontera francesa con España en febrero de 1946, la publicación el 4 de marzo de 1946 de la Nota Tripartita, el anuncio a comienzos de abril del inicio de la consideración del «caso español» por el Consejo de Seguridad de la ONU; o bien, a modo de culminación de todo lo anterior, la Declaración de 12 de diciembre de ese año de condena al régimen español por la Asamblea General de la ONU ${ }^{44}$.

A su llegada a Madrid, Philip W. Bonsal contaba con cuarenta y tres años de edad. Era un hombre avalado por cierta trayectoria. Es de suponer que lo suficientemente sólida como para pensarse en que lograría encarar con garantías los desafíos y dificultades previsibles de un puesto diplomático tan comprometido como era el Madrid de aquellos ańos. Hijo de un conocido periodista ganador del Premio Pulitzer — que también había formado parte del servicio diplomático-, Bonsal junior, antes de ingresar en el Departamento de Estado había trabajado para la multinacional norteamericana de telefonía AT\&T, de la que había llegado a convertirse jefe de su División para Latinoamérica.

McKinzie y Wilson (1971): 16.

Ibid.: 18.

44 Ver Portero (1989). Más concretamente, en relación con los Estados Unidos, ver: PPS/12 «US Policy Toward Spain». Anexo a Mr. George Kennan of the Policy Planning Staff to the Secretary of State and Under Secretary of State (711.52/10-2847), octubre 24, 1947. FRUS 1947 Foreign Relations, Volume III, pp. 1091-1095. Una excelente contextualización histórica se puede encontrar en Hualde Amunarriz (2016): 149-167. 
Hablaba un español fluido. Ingresó en 1937 en la carrera diplomática y fue enviado a La Habana como primer destino. A comienzos de los ańos cuarenta se trasladó a Washington DC y se integró en la Division of the American Republics del Departamento de Estado. A partir de 1941 iría sucesivamente ocupando cargos de mayor responsabilidad: jefe interino de la misma División y, a partir de febrero de 1944, subdirector de la oficina de Asuntos para las Repúblicas Americanas, donde la anteriormente citada Division estaba integrada. En cuanto a los tonos y a la orientación de sus despachos hay que decir que no se situó en posiciones precisamente muy distantes de las de sus predecesores. Una clara prueba de ello — aparte de otros numerosos ejemplos anteriores y posteriores que se podrían aducir - lo constituyó la carta que el 1 de noviembre de 1946 hacía llegar a Outerbridge Horsey, jefe adjunto de la División de Asuntos para Europa Occidental del Departamento de Estado ${ }^{45}$. Como en ocasiones precedentes, en dicha carta Bonsal volvía a mostrarse decididamente contrario a que se adoptasen desde el exterior medidas drásticas contra Espańa. La razón apuntada era doble. Por un lado, el hecho indiscutible, a su juicio, de que «en este momento no hay ninguna alternativa al régimen de Franco" ${ }^{46}$. Por otro, volvía a insistir en las reacciones emocionales que venían despertando en España las acciones de hostilidad y condena producidas en el exterior. Estas, recalcaba Bonsal, ante la falta de alternativas reales al Gobierno de Franco, solo habían servido para que muchos españoles favorables al cambio político concluyeran que «ceder a la presión exterior es tanto antipatriótico como imprudente ${ }^{47}$. En cuanto a la situación en la que se encontraban las fuerzas de la oposición reiteraba los mismos juicios y argumentos de los que ya había echado mano en comunicaciones precedentes ${ }^{48}$. Los cuales

45 NARA RG59/52/1944-1949/Decimal Files/BOX6339 (85200/11-146). De: Philip W. Bonsal A: Outerbridge Horsey, noviembre 1, 1946. Outerbridge Horsey había ingresado en cuerpo diplomático de los EE. UU. en 1938. Tras haber servido como vicecónsul en Budapest, en 1942 fue destinado con el mismo rango a Madrid. De allí se trasladaría a Washington DC en 1944 una vez nombrado jefe adjunto de la División de Asuntos de Europa Occidental del Departamento de Estado.

46 En esa misma carta, Bonsal argumentaba que «si se si se diera el caso que él [Franco] y su régimen hoy fuesen eliminados mediante un ejercicio de coerción exterior, no contaríamos con ningún grupo capaz de hacer funcionar el país y con casi absoluta seguridad sobrevendría un caos político y económico que degeneraría en una guerra civil, cuyo resultado podría muy bien consistir en el advenimiento de una dictadura mucho más repugnante todavía que la actual» (p. 2).

47 Ibid.: 1.

48 En junio de ese año se refería Bonsal al estado de «apatía política, desilusión y agotamiento de amplios sectores de la población espańola cuyo temor a un rebrote de la 
venían a coincidir con los previamente presentados y emitidos tanto por Hayes como por Armour, y también por Butterworth. Concluía el encargado de Negocios que los grupos de la oposición estaban sumidos en un estado inoperante de «desilusión» y de «amargura» ${ }^{49}$.

\section{EL MOMENTO DE PISAR EL ACELERADOR}

Un tema hasta entonces apenas abordado (con excepción de las referencias que Carlton Hayes había dedicado al mismo en su informe de septiembre de 1944) iría cobrando fuerza a largo del año 1946 y del siguiente. Nos referimos, en concreto, al tema de la amenaza de infiltración comunista en España o, más específicamente, al del peligro creciente de penetración soviética que, según se pensaba, parecía cernirse sobre Espańa en caso de prolongarse por más tiempo la permanencia de Franco en el poder. Aunque sería Philip Bonsal, sobre todo, quien más tiempo y espacio iba a dedicar a esta cuestión, en realidad el verdadero arranque de la temática se había producido a principios de febrero de 1946 (coincidiendo con las últimas semanas en Madrid de Butterworth) a raíz de las rotundas manifestaciones sobre España hechas en el telegrama que en la citada fecha se remitía al secretario de Estado, James F. Byrnes, desde la embajada norteamericana en Moscú ${ }^{50}$. Su autor era el por entonces encargado de Negocios en la capital soviética, George F. Kennan. En esta comunicación, quien diecinueve días más tarde, bajo el seudónimo de Mr. X, iba a darse a conocer como el autor del célebre telegrama largo exponía de manera muy persuasiva cómo, movidos por el resentimiento (a causa de la participación española en la campaña contra Rusia durante la guerra), obedeciendo a razones estratégicas (debido a la posición geográfica de una España situada a las puertas del Mediterráneo) y por «considerar que en España existen las mismas condiciones políticas y sociales vigentes en Rusia antes de la Revolución", los comunistas rusos se habían puesto como objetivo hacer fracasar todo intento de que en España tuviese lugar una transición política relativamente ordenada y tranquila $^{51}$. Para lograrlo, continuaba diciendo Kennan, desde el Kremlin se había

guerra civil constituye el más importante as en la manga de Franco» NARA RG59/52/1944-1949/Decimal Files/BOX6338 (852.00/6-546): Incoming Telegram. De: US Embassy, Madrid A: Departamento de Estado, junio 5, 1946, p. 2.

49 Carta. De: Philip W. Bonsal A: Outerbridge Horsey, p. 2.

50 "The Chargé in the Soviet Union (Kennan) to the Secretary of State» (752.61/2346), febrero 3, 1946, en FRUS, 1946, Volume V, pp. 1033-1036.

51 "The Chargé in the Soviet Union (Kennan) to the Secretary of State... p. 1033. 
optado por presionar a la opinión pública internacional para forzar a los Gobiernos occidentales a aplicar contra Espańa una dura política de sanciones económicas, a fin de provocar una inmediata caída de Franco. Lo cual, concluía el diplomático norteamericano, haría de la península ibérica un campo abonado para una conquista violenta del poder por los comunistas.

Al final de su relativamente extenso telegrama, Kennan solicitaba que se pidiera a la embajada de Madrid su opinión sobre la cuestión. Esta se dio a conocer mediante el telegrama que Butterworth remitiría a Washington doce días más tarde ${ }^{52}$. El contenido resulta interesante, al quedar ya delineado el razonamiento del que, apoyándose en Butterworth, poco más adelante Bonsal iba a echar mano para transmitir al Departamento de Estado la idea de que la prolongación de Franco en el poder incrementaba exponencialmente el riesgo de que se desencadenase una involución comunista en España. Pues, en efecto, según había expuesto Butterworth, la habilidad mostrada por Franco para sacar tajada de los temores de los espańoles a un reinicio de la guerra civil estaba llevando a los sectores más moderados a aproximarse cada vez más a su persona. Todo eso - continuaba diciendo- provocaba como efecto rebote que «el centro político de gravedad entre la oposición a Franco se est[é] moviendo progresivamente hacia la izquierdan; de modo — concluía — que se multiplicaban las posibilidades de un estallido violento que proporcionaría a los comunistas «las mayores ventajas, así como el derecho consiguiente a reclamar el liderazgo de las fuerzas "democráticas" " 53 . Como se acaba de decir, apoyándose en todas estas ideas y razonamientos, a lo largo de los meses siguientes una y otra vez alertaría Bonsal a Washington de la grave amenaza que para la unidad interior y la estabilidad de España suponía dicho traslado hacia la izquierda del centro de gravedad de la oposición a la dictadura ${ }^{54}$. Así, en la ya citada carta a Horsey ${ }^{55}$, el Chargé insistía ante su interlocutor hasta

52 "The Chargé in Spain (Butterworth) to the Secretary of State» (852.00/2-1546), febrero, 15, 1946 en FRUS, 1946 Volume V, pp. 1038-1042. Un segundo telegrama de Kennan sobre el mismo tema se enviaría al secretario de Estado el 1 de marzo una vez recibidos los comentarios de la embajada en Madrid solicitados en el telegrama de febrero. Ver: «The Chargé in the Soviet Union (Kennan) to the Secretary of State» (751.52/3-146), marzo 1, 1946 en FRUS, 1946 Volume V, pp., 1044-1045.

53 Ibid:: 1040.

54 Ver, a este respecto, NARA RG59/52/1944-1949/Decimal Files/BOX 6338. «De: Bonsal A: Secretaría de Estado. Telegrama (852.00/3-2946), marzo 29, 1946, p. 3; NARA RG59/52/1944-1949/Decimal Files/BOX 6338. De: Bonsal A: Secretario de Estado: Principal Monarchist Developments Since the Middle of April» (852.00/52848) CS/V, mayo 28, 1946, p. 5.

55 Ver nota 49. 
qué punto la tesis de que «cuanto más tiempo continúe Franco en el poder más intenso será el giro hacia la izquierda y el peligro de una revuelta violenta [...] es un asunto que se ha abordado con frecuencia y que creo se ha estudiado en los informes de la embajada». Inmediatamente después, Bonsal hacía mención al telegrama sobre esa cuestión enviado al Departamento de Estado por su predecesor el 15 de febrero, y concluía afirmando que el planteamiento que en dicho telegrama se exponía «is a sound one and the Russians know it ${ }^{56}$.

No existen evidencias suficientes para determinar con exactitud el efecto inmediato que las palabras de Philip Bonsal a Outerbridge Horsey pudieron causar en el seno del Departamento de Estado. Sin embargo, lo cierto es que, con el paso de los meses, entre los responsables de la acción exterior norteamericana cada vez pareció darse más rotundamente por sentado que para que se iniciara en España un proceso de cambio político ya no se podía esperar más y que era imprescindible actuar, dejando muy claro a todos los agentes de la sociedad española, tanto dentro como fuera del gobierno: a) que en ningún caso se pensaba ni contar con los comunistas ni adquirir compromisos de ningún tipo con los representantes del Gobierno republicano en el exilio; b) que nada que pusiera en jaque la integridad de España o que se situara al margen de la voluntad de los propios españoles iba a contar con el respaldo norteamericano, y c) que para poderse aspirar a una colaboración del exterior la condición primera era que Franco saliera lo antes posible del poder, porque su permanencia en el mismo ponía en serio riesgo la estabilidad y unidad interna de España y porque, si bien el dictador español «es un corderito cuando lo comparamos con Tito o con Stalin» [...] el sentimiento mundial contra él es tal que no queda otra alternativa [que su salida del poder]».

Los puntos que se acaban de exponer, así como las citas textuales del párrafo anterior, proceden del memorándum que Paul T. Culbertson, por entonces jefe de la División de Asuntos para Europa Occidental, hacía llegar al director en funciones de la Oficina de Asuntos Europeos del Departamento de Estado, John D. Hickerson, en febrero de $1947^{57}$. Este informe, por otro

56 Carta. De: Philip W. Bonsal A: Outerbridge Horsey, p. 1.

57 NARA RG59/52/1944-1949/Decimal Files/BOX6339 (852.00/2-1477): De: Paul T. Culbertson, jefe de la División de Asuntos Europeos del Departamento de Estado A: John D. Hickerson, director en funciones de la Oficina de Asuntos Europeos, Departamento de Estado, febrero 14, 1947, pp. 1-2. Este memorándum se basaba, como indicaba Culbertson, en el conjunto de informes sobre la situación espańola recibidos en los últimos meses en la División de Asuntos de la Europa Occidental de diversas fuentes, tanto de dentro como de fuera de España. John D. Hickerson, que hablaba 
lado, había sido precedido por otro anterior, asimismo enviado a Hickerson quince días antes, en el cual sus dos autores (los ya citados Culbertson y Horsey) habían concluido que: a) dado que el régimen de Franco se ha mostrado incapaz de resolver los graves problemas económicos de Espańa, de tal forma que «la penuria resultante es generalizada y cada vez más seria»; b) dado que el espejismo de que Franco sería depuesto a resultas de una intervención exterior se ha ido desvaneciendo — de modo que en la oposición ha comenzado a comprenderse «que el cambio político en España ha de iniciarse y llevarse a cabo en gran medida mediante una acción efectiva de los mismos españoles»—-, y c) dado que «el mismo Franco, y muchos de sus apoyos, reconocen que la "evolución" del régimen es necesaria", entonces había llegado el momento de que «los EE. UU. y Gran Bretaña (con la cooperación, quizás, del Vaticano) aceleren la salida de Franco, proporcionando un decisivo aliento a determinados sectores españoles», por mucho — se continuaba diciendoque dicho cambio «might not result in the formation of the type of régime which we would most prefer to see established $»^{58}$.

El documento que acabamos de considerar resultaba además relevante porque en él se aludía, con renovado énfasis, al tipo de relación que se consideraba oportuno y deseable mantener con las fuerzas de la oposición. En lo primero en que se insistía era en alentar a que la oposición no comunista (calificada habitualmente en la documentación como la oposición «moderada» o de "centro») lograra superar en cuanto antes el estado de división en que se encontraba. Se entendía que un poderoso incentivo para lograr ese objetivo

un fluido español, había sido jefe adjunto de la Division of Western European Affairs entre 1928-1943. También iba a ser nombrado consejero de la delegación estadounidense en la cumbre de Dumbarton Oaks. Más sobre su figura en McKinzie (1972 y 1973).

58 NARA RG59/52/1944-1949/Decimal Files/BOX6339 (852.00/1-3047) De: Division of Western European Affairs A: Office of European Affairs, enero 30, 1947. Las cursivas son nuestras. En cuartilla firmada por Hickerson adjunta al citado documento se reproducía la siguiente reflexión del director de la Oficina de Asuntos Europeos: «Yo no creo que el Gobierno soviético desee ver al régimen de Franco reemplazado del poder a menos que sea sucedido por un Gobierno en el que la influencia comunista sea fuerte, si acaso no predominante. Pienso que el Gobierno soviético probablemente ve a Franco como un valioso as en la manga en sus negociaciones con los Estados Unidos y con el Reino Unido. Lamentablemente, también creo que cuanto más tiempo permanezca Franco en el poder mayor será la posibilidad de que acabe siendo reemplazado por un régimen en el que la influencia comunista sea grande». La cuartilla aparecía también con fecha de 30 de enero. Las cursivas del texto que se acaba de reproducir son nuestras. 
podía ser la puesta en marcha, a instancias de los Estados Unidos y Gran Bretańa, de una "acción política positiva» dirigida a ganarse a esos mismos elementos centristas de la oposición (the Center elements of the opposition), así como al Ejército59. El contenido de esa acción política había de consistir, se explicitaba líneas más abajo, en ofrecer a sus destinatarios sólidas garantías de que, una vez desplazado Franco del poder y formado un nuevo Gobierno comprometido con la celebración de elecciones libres, con la libertad de prensa y con la libertad de reunión, se obtendría de manera inmediata el reconocimiento diplomático de Londres y de Washington, además de la asistencia económica necesaria para «aliviar las penurias económicas de España», y para que el país «reemprenda de nuevo el lugar que le corresponde en la colectividad organizada de naciones» ${ }^{60}$. Todo ese curso de acción — se concluía«había de darse a conocer a las facciones de Centro [sic] de la oposición y quizás también a algunas autoridades españolas» ${ }^{61}$.

Sin embargo, es preciso resaltar también que la eventualidad de que en España se llegara a producir un vacío de poder, ya fuera a causa de una situación económica cada vez más insostenible o por los déficits organizativos y políticos internos de la oposición no comunista para presentarse con garantías como alternativa a la dictadura de Franco, continuó siendo el factor principal que se interpuso en las relaciones mantenidas por los EE. UU. con los representantes de las fuerzas opositoras. Consustancial con ese temor fue la adopción de una estrategia basada en el dejar hacer, con el objeto de no adquirir de momento con la oposición compromisos o cualquier otro tipo de obligaciones. $\mathrm{Al}$ menos hasta que entre todos sus grupos y tendencias no se acordara un pacto de unidad nacional, lo suficientemente amplio y flexible como para granjearse el apoyo del Ejército y de otros sectores moderados del régimen. Lo que se acaba de exponer constituyó la columna vertebral de la política norteamericana hacia España entre septiembre de 1944 y diciembre de 1947, como abundantemente se desprende de la lectura de la masa documental generada, a raíz de los contactos mantenido entre la embajada en Madrid y la Secretaría de Estado y el Departamento de Estado. En la práctica, eso mismo significaba una negativa de parte de Washington a conceder a los grupos de la oposición suerte alguna de apoyo explícito, por muy moderados y anticomunistas que pudieran ser (eventualidad que, sin duda, hubiera reforzado su legitimidad), hasta que no hubiesen dado por sí mismos todos los pasos para presentarse de manera convincente como una alternativa real a Franco. Todo lo cual no

\footnotetext{
59 Ibid.: 2.

60 Íd.

61 Íd.
} 
impidió que desde la embajada fueran constantes - y crecientes- los contactos informales con los representantes de la oposición, aunque siempre para instarles a que progresaran por el camino de la unidad y de la concordia o que avanzaran en un proceso de convergencia con los sectores más moderados del régimen, incluyendo al Ejército.

\section{UN ÚLTIMO ESFUERZO ANTES DEL GIRO}

En relación con la evolución política de la oposición, aun con algunos matices, las estimaciones en la embajada fueron generalmente optimistas hasta marzo de 1947. A partir de esa fecha las esperanzas en un próximo gran acuerdo, en torno sobre todo a los socialistas y los sectores conservadores monárquicos, se fueron enfriando de manera paulatina ${ }^{62}$. De hecho, a principios de mayo de ese año, virtualmente en vísperas de producirse su marcha a París (donde ocuparía el puesto de consejero de la embajada de los EE. UU. en la capital francesa), Philip Bonsal escribía una muy esclarecedora carta a Samuel Reber, director de la oficina del Departamento de Estado para Asuntos Europeos, en la que, en un tono de confidencia, le confesaba su pérdida de confianza en que alguna vez los grupos de la oposición llegaran a mostrarse capaces de superar sus diferencias personales. El problema de fondo - concluía de manera sombría el todavía encargado de Negocios - era que carecían de la «masa gris, del músculo y de la fuerza necesaria para convertirse en una oposición política efectiva dentro del régimen». Todo eso — añadía - ciertamente «es lamentable, pero es la verdad». Y lo era - concluía Bonsal - precisamente en el momento en que Franco «ha logrado con gran éxito que se vuelvan a despertar las emociones de la guerra civil y el poder político del país en estos momentos está casi por completo en las manos de quienes ganaron la guerra civil ${ }^{63}$.

62 Ver, entre otros, NARA RG59/52/1944-1949/Decimal Files/BOX6339 (852.00/31147CS/V). De: Bonsal A: Secretaría de Estado, marzo 11, 1947; RG59/52/19441949/Decimal Files/BOX6339 (852.00/3-1347CS/A): De: Bonsal A: Secretaría de Estado «Political Observation of a Spanish Socialist of Prieto Tendency», marzo 13, 1947; RG59/52/1944-1949/Decimal Files/BOX6339 (852.00/4-347CS/V). De: Bonsal A: Secretaría de Estado. «Conversation of a Member of the British Embassy with General Antonio Aranda», abril 3, 1947 y RG59/52/1944-1949/Decimal Files/ BOX6340 (852.00/6-1247CS/A). De: Bonsal A: Secretaría de Estado. «Political Developments», junio 12, 1947.

63 NARA RG59/52/1944-1949/Decimal Files/BOX6340 (852.00/5-147): Carta. De: Philip W. Bonsal A. Samuel Reber, mayo 1. 1947, p. 1. 
La marcha definitiva de Philip Bonsal de Madrid tuvo lugar a finales del mes de junio. Coincidiendo con ella enviaba un último escrito oficial al Departamento de Estado, en el que a modo de despedida planteaba qué era lo que a su juicio aún cabía por hacer para revertir la situación de reforzamiento progresivo de la posición de Franco en el seno del régimen ${ }^{64}$. La conclusión a la que llegaba no era realmente novedosa en su sustancia. Pues, al igual a lo ya señalado por sus predecesores, aludía también Bonsal a la inexistencia de una alternativa al régimen vigente capaz de asegurar el orden interior, además de evitar que el país acabara adentrándose de nuevo por la senda de la confrontación. Sin embargo, llamaba la atención la severidad de los términos de los que echaba mano para destacar la — a su juicio- completa inanidad de la oposición antifranquista (de la que decía que, ni existía desde el punto de vista operativo ni nada indicaba que de momento fuera a cristalizar). En consonancia con tales juicios, en este último escrito también se esforzaba Bonsal por insistir con redoblado énfasis en la idea, ya formulada meses atrás, de que convenía ir resituando el foco de atención en los sectores más moderados del régimen - y no tanto en los de la oposición - para conseguir que se fueran distanciando de Franco. Así pues, tras tantas dudas y cavilaciones, para Bonsal era ya llegado el momento de que Londres y Washington se decidieran a aunar voluntades y de que convergieran en una política común hacia España meticulosamente medida, en la que se compaginara la más absoluta firmeza en el fondo con la mayor suavidad posible en las formas. Solo de este modo - argumentaba el diplomático norteamericano, evitándose en todo momento desplegar unas actitudes negativas fundadas en la lógica del premio y del castigo- se lograría contrarrestar el lugar común de una España incomprendida en el extranjero y calumniada desde hace más de tres siglos, tan hábilmente manejada por Franco para manipular en su beneficio los sentimientos nacionalistas de los españoles. A la par que eso, con una política como aquella se conseguiría también — continuaba argumentando Bonsal- quitar de la cabeza a tantos colaboradores de Franco, de una vez por todas, la idea de que el Gobierno de los Estados Unidos no es sincero cuando afirmaba públicamente que en ninguna circunstancia "prestará su ayuda política o económica al actual régimen español» ${ }^{65}$.

Si Bonsal, como vemos, en el momento de su despedida de Espańa estaba abogando por no esperar nada de las fuerzas de la oposición y por exhibir ante

64 NARA RG59/52/1944-1949/Decimal Files/BOX6340 (852.00/6-2647). De: Philip W. Bonsal A: John D. Hickerson; Samuel Reber y Outerbridge Horsey, junio 26, 1947.

65 Ibid.: 2. 
el régimen una política de firmeza en el fondo, pero suave en las formas, también por eso mismo pareció inclinarse, al menos inicialmente, el nuevo encargado de Negocios, Paul T. Culbertson, lo que, por lo demás, quizás no debiera resultarnos sorprendente porque antes de producirse su nombramiento llevaba ya tres meses trabajando conjuntamente con Bonsal en la embajada en Madrid (primero como primer secretario y, más adelante, como consejero), a la que se había incorporado en abril de 1947 desde su cargo anterior de jefe de la División de Asuntos para Europa Occidental del Departamento de Estado, puesto que venía ocupando desde $1944^{66}$.

Sin embargo, hacia finales del mes de octubre, en un relativamente largo telegrama, Culbertson, aunque sin proponer explícitamente ningún cambio de rumbo, al final de su comunicación se hacía la pregunta de si, dada la capacidad de aguante exhibida por Franco y su manifiesta voluntad de perpetuarse en el poder, dado el estado de inoperancia de la oposición al régimen y, sobre todo, dada una situación mundial de enfrentamiento bipolar creciente, no habría llegado ya el momento de considerar la posibilidad de modificar o no la política hasta entonces seguida en Washington hacia el caudillo español ${ }^{67}$. Las circunstancia que llevó a que, por primera vez que tengamos constancia, se verbalizara una reflexión de ese tenor por parte de un representante oficial de los Estados Unidos no fue otra sino la conversación que el Chargé había mantenido con José Sebastián de Erice, director general del Ministerio de Exteriores español, a propósito de la reciente reunión mantenida por Ernest Bevin, secretario del Foreign Office, con los dos líderes de la oposición socialista y monárquica española, Indalecio Prieto y José María Gil Robles ${ }^{68}$. Como relataba Culbertson en su telegrama de 23 de octubre ${ }^{69}$, en el curso de dicho

66 Una interesante semblanza de Culbertson se puede encontrar en Foreign Service Journal (November 1953), p. 44.

67 NARA RG59/52/1944-1949/Decimal Files/BOX6340 (852.00/10-2347A/VS). De: Culbertson A: Secretaría de Estado, octubre 23, 1947, p. 3.

68 La reunión entre Prieto y Bevin tuvo lugar el 26 de septiembre. Gil Robles, por su parte, se reunió con el ministro de Exteriores británico el 19 octubre. Sobre estas dos entrevistas, y sobre la reunión mantenida entre sí por los dos dirigentes españoles, asimismo en Londres, ver NARA RG59/52/1944-1949/Decimal Files/BOX6340 (852.00/10-347). De: Embajada US, Londres A: Secretaría de Estado, octubre 3, 1947. Clasificados en esa misma Caja 6349 también se encuentran los siguientes telegramas: (852.00/10-947). De: Embajada US, Londres A: Secretaría de Estado. Octubre 9, 1947; (852.00/10-2047A/VS). De: Embajada US, Londres A: Secretaría de Estado, octubre 20, 1947 y (852.00/10-2347A/VS). De: Embajada US, Londres A: Secretaría de Estado, octubre 23, 1947.

69 Ver nota n. 66. 
encuentro el diplomático español le había echado en cara que los Gobiernos occidentales, especialmente el norteamericano y el británico, nunca tuvieran en cuenta que "España quería liberalizarse y evolucionar hacia una situación más liberal ${ }^{70}$. Aunque ante esas palabras el representante de los Estados Unidos en Madrid, según su propia confesión, prefirió «no corregirle [a de Erice] recordándole que nuestra política no contempla [una] evolución bajo Franco", sin embargo eso no fue óbice para que el mismo Culbertson acabara cuestionándose hasta qué punto eso debía seguir siendo así o si acaso el Departamento de Estado «in light of world developments as they are envisages possibility of policy modification or not $»^{71}$.

En realidad, quien por aquellas fechas mucho más que vislumbrando la posibilidad de un cambio de política sabemos que la estaba postulando (y no con poca vehemencia) era George F. Kennan, el flamante primer director del recién creado, apenas cuatro meses antes, Policy Planning Staff ${ }^{72}$. En efecto, con fecha de 24 de octubre Kennan remitía a George Marshall y a Robert A. Lovett, secretario de Estado y subsecretario de Estado respectivamente, un memorándum en el que se cuestionaba seriamente la política que venía practicando el Departamento de Estado respecto a España, llegándose a sugerir su sustancial modificación. El memorándum en cuestión había sido solicitado al PPS a instancias de un buen conocedor de las circunstancias españolas, Norman Armour, por entonces subsecretario de Estado para Asuntos Políticos. La argumentación desarrollada por Kennan, incluida en el largo anexo que acompañaba a este documento, se fundamentaba en dos afirmaciones principales. Primero, en el fracaso cosechado en el objetivo de forzar la salida de Franco mediante una política de aislamiento internacional de España. Estrategia que, a juicio del director del PPS, solo había servido para que «el general Franco siga firmemente en el poder y para que su régimen se haya visto de hecho reforzado debido a las manifestaciones de hostilidad internacional $»^{73}$. En segundo lugar, en la falta total de evidencias disponibles acerca de la existencia de «una oposición real a Franco, dentro o fuera de España, capaz de procurar un cambio ordenado de Gobierno» ${ }^{74}$. En consecuencia, se

\section{Ibid:: 3 .}

71 Íd. Echando mano del popular proverbio inglés «in any way upset the applecart here regardless of number of rotten apples in cart», Culbertson concluía que no era el momento de provocar antagonismos entre Espańa y los Estados Unidos.

72 Gaddis (2011): 264-275 y Hualde Amunarriz (2016): 189-206.

73 PPS/12 Annex: «US Policy Toward Spain», octubre 24, 1947 en FRUS, 1947, Vol. III, p. 1092.

74 Ibid.: 1093. 
abogaba en el citado anexo por una «normalización» inmediata en las relaciones bilaterales entre los EE. UU. y España, para lo cual se recomendaba la eliminación de las restricciones económicas hasta entonces vigentes - a fin de favorecer la apertura de España a transacciones económicas de carácter privado y a una posible asistencia financiera-; la adopción en las Naciones Unidas de unas actitudes favorables a la rescisión de la resolución de condena de diciembre de 1946, y el bloqueo de todo intento de llevar adelante una nueva resolución que contemplara la aprobación de sanciones económicas contra Espańa. El memorándum y el anexo fueron devueltos a Kennan con la anotación «approved by indication of G. C. Marshall» $»^{5}$.

Este nuevo curso en la política hacia España recomendado por el PPS comenzó a hacerse efectivo a raíz del telegrama recibido por Paul Culbertson el 18 de diciembre de 1947. En dicha comunicación se informada al encargado de Negocios que, al cabo de un minucioso estudio, en el Departamento de Estado se había llegado a la conclusión de que «nuestra prioridad en estos momentos debe consistir en proceder gradualmente a una normalización de relaciones, tanto políticas como económicas [con España] [...]» ${ }^{76}$. En suma, desde finales de 1947 en adelante, las relaciones de Espańa con los Estados Unidos comenzaban a adoptar un nuevo curso cuya primera etapa de desarrollo comenzó a arrancar a partir de enero de 1950.

\section{CONCLUSIÓN}

El 31 de octubre de 1949, Dean Acheson, ya por entonces secretario de Estado, enviaba a Culbertson un telegrama en el que le anunciaba que no había de esperarse más en la incorporación de España al programa de la USIE ${ }^{77}$. La integración del país en los circuitos de la diplomacia pública norteamericana daba

75 Ibid.: 1092. Sobre la «intrahistoria» de la elaboración y aprobación del draft de 24 de octubre ver Hualde Amunarriz (2016): 199-206.

76 NARA, RG 59/52/1945-1949/Decimal Files/BOX 6340 (852.00/12-1847): Outgoing Telegram. De: Departamento de Estado A: Embajada US, Madrid, diciembre 18, 1947, p. 1. Este telegrama aparece también publicado en FRUS, 1947, Vol. III, pp. 1096-1097. El telegrama estaba firmado por Richard A. Lovett, sustituto de Dean Acheson en la Subsecretaría de Estado desde el 1 de julio de 1947.

77 Telegrama. De: Dean Acheson A: Paul T. Culbertson. Octubre 31, 1949, en FRUS, 1949, Volume IV, p. 763. La USIE [United States Information and Educational Program] se creó el 27 de enero de 1948. Sobre esta cuestión ver Scott-Smith (2015); Montero Jiménez (2009); Delgado (2009a y 2014); León Aguinaga (2009), y Niño y Montero (2012). 
comienzo ${ }^{78}$. También formando parte de la misma dinámica, el 4 de noviembre de 1950 tenía lugar la revocación por la Asamblea General de la ONU de la resolución de condena de Espańa de 1946. Apenas cuatro meses más tarde, en marzo de 1951, se producía la llegada de Stanton G. Griffis a Madrid como nuevo embajador norteamericano (seis años después de la salida del país del último representante de los EE. UU. con ese rango). El proceso de normalización y de colaboración entre los Gobiernos español y norteamericano continuaría dando pasos adelante en los años siguientes: en septiembre de 1953 se ponía definitivamente fin al aislamiento internacional de España con la firma de los acuerdos defensivos y de cooperación económica con los Estados Unidos, mientras que en octubre de 1958 se producía la incorporación española al Programa Fulbright ${ }^{79}$. Un momento culminante en esa dinámica se produjo a raíz de la visita oficial a España del presidente Eisenhower el 21 de diciembre de 1959. A pesar de lo dicho, entre la clase política norteamericana, así como en su opinión pública, la persona de Franco continuaba despertando no pocas reticencias (y continuaría haciéndolo). Sin embargo, por razones muy semejantes a las que acabaron prevaleciendo a finales de 1947, la realidad política vigente en España continuó percibiéndose como la única opción viable y realista para alejar definitivamente a España de los fantasmas del pasado y para que el país lograra progresar hacia un futuro democrático. Aunque — ciertamente - no es posible determinar documentalmente en qué medida los argumentos que hemos estado repasando contribuyeron a que, en el seno del Departamento, de Estado la balanza se fuera inclinando hacia el predominio de unas actitudes hacia el régimen español cada más pragmáticas y posibilistas, la sola existencia desde meses antes de la finalización de la Segunda Guerra Mundial de una línea tan clara, tan coherente, y tan sostenida en el tiempo de encarar la cuestión española a nivel de la embajada estadounidense en Madrid es ya de por sí algo que creemos suficientemente relevante. Por otro lado, en consideración a los espacios de influencia (al menos potencialmente) ocupados, antes o después de sus respectivos paso por España, por algunos de estos nombres en el seno del Departamento de Estado, o también en atención a las relaciones personales fraguadas con otros funcionarios del Departamento, tampoco parece demasiado aventurado pensar que aquellos argumentos acabaran actuando a modo de contrapeso frente a actitudes más severas, y como tales mucho menos dispuestas a consentir que una figura como Franco pudiera llegar a salir políticamente indemne de la derrota final de los fascismos ${ }^{80}$.

\footnotetext{
Ver Delgado (2011 y 2016).

Ver Delgado (2009b y 2015).

80 Es interesante recordar a este respecto que una figura como Norman Armour llegara a ser promocionado al cargo de secretario adjunto de Estado para Asuntos Políticos entre
} 


\section{Bibliografía}

Alonso García, M. R. (2004). Historia, diplomacia y propaganda de las instituciones de la República en el exilio (1945-1962). Madrid: Fundación Universitaria Española.

Bowen, W. H. (2016). Con la mayor reticencia: Harry Truman, Francisco Franco y la alianza España-Estados Unidos. En J. M. Thomàs (coord.). Estados Unidos, Alemania, Gran Bretaña, Japón y sus relaciones con España entre la guerra y la post-guerra (1939-1953) (pp. 63-101). Madrid: Universidad Pontificia Comillas.

- (2017). Truman, Franco's Spain and the Cold War. Columbia: University of Missouri Press.

Brundu Olla, P. (1985). Ostracismo e Realpolitik. Gli Alleati e la Spagna franchista negli anni del dopoguerra. Cagliari: CELT.

Cortada, J. W. (1980). The United States. En J. W. Cortada (ed.). Spain in the Twentieth-century World. Essays on the Spanish Diplomacy, 1898-1978. London: Aldwych.

Delgado, L. (2009a). La maquinaria de la persuasión. Política informativa y cultural de Estados Unidos hacia España. Ayer, 75, 97-132.

- (2009b). Viento de poniente. El Programa Fulbright en España. Madrid: Comisión Fulbright Espańa; LID Empresarial; Agencia Española de Cooperación Internacional.

(2011). Objetivo: atraer a las élites. Los líderes de la vida pública y la política exterior norteamericana en España. En A. Niño y J. A. Montero (eds.). Guerra Fría y Propaganda. Estados Unidos y su cruzada cultural en Europa y América Latina (pp. 235-276). Madrid: Biblioteca Nueva.

(2014). La diplomacia pública de Estados Unidos. Una perspectiva histórica. Revista Complutense de Historia de América, 40, 277-301. Disponible en: https:/doi.org/ 10.5209/rev_RCHA.2014.v40.46352.

(2015). Modernizadores y tecnócratas. Estados Unidos ante la política educativa y científica de la España del desarrollo. Historia y Política, 34, 113-146. Disponible en: https://doi.org/10.18042/hp.34.05.

(2016). Estados Unidos, ¿soporte del franquismo o germen de la democracia? En L. Delgado, R. Martín de la Guardia y R. Pardo (coords.). La apertura internacional de España. Entre el franquismo y la democracia (1953-1986) (pp. 263-307). Madrid: Sílex.

julio de 1947 y julio de 1948. Por su parte, Paul T. Culbertson, —que, entre otros puestos, había sido jefe de la División de Asuntos de la Europa Occidental—, no era ni por experiencia ni por trayectoria precisamente un cualquiera en el seno de Departamento de Estado. Tampoco podía considerarse un cualquiera a Philip W. Bonsal. Este, además de contar asimismo con una trayectoria previa nada despreciable, según se desprende de la documentación mantenía una relación estrecha con Samuel Reber, director de la Oficina para Asuntos Europeos del Departamento de Estado, y con Outerbridge Horsey, uno de los más reputados especialistas sobre asuntos de España en la División de Asuntos de Europa occidental del Departamento de Estado. Por su parte, a William W. Butterworth le unían con George F. Kennan unos estrechos lazos de amistad y camaradería forjados en sus años de compañeros universitarios en Princeton. 
Dunham, W. B. (1996). Memoirs. Association for Diplomatic Studies and Training. Foreign Affairs Oral History Project. Foreign Affairs Series. Disponible en: https://adst.org/.

Edwards, J. (1999). Anglo-American Relations and the Franco Question 1945-1955. Oxford: Clarendon Press. Disponible en: https://doi.org/10.1093/acprof:oso/9780198228714. 001.0001 .

Gaddis, John L. (2011). George F. Kennan: An American Life. New York: Penguin Press.

Hualde Amunarriz, X. (2016). El «cerco» aliado. Estados Unidos, Gran Bretaña y Francia frente a la Dictadura Franquista (1945-1953). Bilbao: Universidad del País Vasco.

Jarque Íńiguez, A. (1998). "Queremos esas bases». El acercamiento de Estados Unidos a la España de Franco. Madrid: Universidad de Alcalá.

León Aguinaga, P. (2009). Los canales de la propaganda americana. Ayer, 75, 133-158.

Liedtke, B. N. (1998). Embracing a Dictatorship. US Relations with Spain, 1945-53. Houndsmil: Macmillan Press LTD. Disponible en: https://doi.org/10.1007/978-1-349-26112-3.

McKinzie, R. D. (1972). Oral History Interview with John D. Hickerson. Disponible en: https://bit.ly/3153Loy.

- (1973). Oral History Interview with John D. Hickerson. Disponible en: https://bit. ly/3A80c5i.

McKinzie, R. D. y Wilson, T. A. (1971). Oral History Interview with W. Walton Butterworth. Disponible en: https://doi.org/10.2307/4004333.

Miscamble, W. D. (1992). George F Kennan and the Making of American Foreign Policy, 19471950. New Jersey: Princeton University Press.

Montero Jiménez, J. A. (2009). Diplomacia pública, debate político e historiografía en la política exterior de los Estados Unidos. Ayer, 75, 63-95.

Niño, A. y Montero, J. A. (eds.) (2012). Guerra Fría y propaganda. Estados Unidos y su cruzada cultural en Europa y en América Latina. Madrid: Biblioteca Nueva.

Portero, F. (1989). Franco aislado. La cuestión española (1945-1950). Madrid: Aguilar.

Scott-Smith, G. (2015). US Public Diplomacy and Democracy: Promotion in the Cold War, 1950s-1980s. En F. J. Rodríguez, L. Delgado y N. J. Cull (eds.). US Public Diplomacy and Democratization in Spain. Selling Democracy? New York: Palgrave Macmillan. Disponible en: https://doi.org/10.1057/9781137461452_2.

Termis Soto, F. (2005). Renunciado a todo. El régimen franquista y los Estados Unidos desde 1945 hasta 1963. Madrid: Biblioteca Nueva.

Thomàs, J. M. (2011). Roosevelt, Franco and the End of World War II. New York: Palgrave Macmillan. Disponible en: https://doi.org/10.1057/9780230118676.

- (2016). Catolicismo, antitotalitarismo y franquismo durante la Segunda Guerra Mundial y la inmediata postguerra: Carlton J. H. Hayes y España. En J. M. Thomàs (coord.). Estados Unidos, Alemania, Gran Bretaña, Japón y sus relaciones con España entre la guerra y la postguerra (1939-1953) (pp. 38-42). Madrid: Universidad de Comillas.

Viñas, Á. (1981). Los pactos secretos de Franco con Estados Unidos. Bases, ayuda económica, recortes de soberanía. Barcelona: Grijalbo.

Yuste de Paz, M. Á. (2005). La II República española en el exilio de los inicios de la Guerra Fría (1945-1951). Madrid: Fundación Universitaria Española. 